\title{
A colorimetric DET technique for the high-resolution measurement of two-dimensional alkalinity
}

\section{distributions in sediment porewaters}

William W. Bennett*, David T. Welsh, Antoine Serriere, Jared G. Panther, and Peter R. Teasdale

Environmental Futures Research Institute, Griffith School of Environment, Griffith University

Gold Coast campus, Queensland 4222, Australia

*Corresponding Author: w.bennett@griffith.edu.au 


\begin{abstract}
Measurements of porewater alkalinity are fundamental to the study of organic matter mineralization in sediments, which plays an essential role in the global cycles of carbon and nutrients. A new colorimetric diffusive equilibration in thin film (DET) technique is described for measuring twodimensional total alkalinity distributions in sediment porewaters at high-resolution $\left(1-2 \mathrm{~mm}^{2}\right)$. Thin polyacrylamide hydrogel layers $(0.8 \mathrm{~mm})$ equilibrate with the porewater and, after removal, are immediately laid onto another hydrogel containing formic acid, which reacts with alkalinitygenerating species, and the pH-indicator bromophenol blue. The resultant color change is quantified using computer-imaging densitometry. The lower limit of detection is 0.2 meq $\mathrm{L}^{-1}$ and the upper measurement limit is 8 meq $\mathrm{L}^{-1}$. Deployment in seagrass colonized sediment revealed high levels of spatial heterogeneity in the porewater alkalinity distribution, with concentrations ranging from 2.28 meq $\mathrm{L}^{-1}$ in the overlying water to 5.13 meq $\mathrm{L}^{-1}$ in some parts of the sediment. This is the first time that two-dimensional, high-resolution distributions of porewater alkalinity have been measured.
\end{abstract}

Keywords: alkalinity, DET, porewater, biogeochemistry, high-resolution, two-dimensional 


\section{Introduction}

The measurement of alkalinity in sediment porewaters is essential for understanding the cycling of carbon within aquatic environments, ${ }^{1-3}$ acidification processes in lakes ${ }^{4}$ and rivers, ${ }^{5}$ and can assist with interpretation of biogeochemical processes. ${ }^{6}$ Shallow coastal sediments have been identified as important alkalinity generators, which increase the $\mathrm{CO}_{2}$ buffering capacity of the oceans and thus act to mitigate anthropogenic carbon emissions. ${ }^{7}$ Organic matter mineralization within sediment via aerobic or anaerobic (denitrification and reduction of iron, manganese and sulfate) microbial metabolism, generates bicarbonate and other components of total alkalinity, such as sulfide (HS`). ${ }^{3,8}$ Unfortunately, while simple and effective methods of measuring alkalinity in surface water samples have been developed, ${ }^{2}$ measurements in sediment porewaters are more difficult and have been studied to a lesser degree.

Sediment porewaters are a challenging matrix in which to measure alkalinity due to the inherently small volumes able to be collected and, particularly in productive coastal sediments, the numerous biogeochemical processes occurring on fine spatial scales. ${ }^{9-11}$ Current approaches to measuring porewater alkalinity involve extraction of a sufficient porewater volume, typically by centrifugation or squeezing, and analysis by a potentiometric or single-point titration., 12 These procedures are time and labor intensive, and typically only provide depth profiles of alkalinity at low (cm) resolution. This spatial resolution has been shown to be unrepresentative of many biogeochemical processes, which can often vary in two dimensions at the millimeter scale. ${ }^{9,}{ }^{11}$ Conventional methods are also subject to artifacts associated with the mixing of reactive substances that were spatially separated within the porewaters. These effects are likely to cause a number of undesirable reactions, including the oxidation/reduction, and/or precipitation/dissolution of species such as ferric and ferrous iron, and sulfide, which may lead to inaccurate alkalinity measurements and questionable interpretation of sediment biogeochemistry. ${ }^{10}$ 11, 13, 14 Existing techniques such as planar optodes and in situ microelectrodes can overcome some of the problems with conventional sampling, and are powerful tools for investigating particular analytes, but no methods currently exist for measuring alkalinity. A 
technique was recently developed, based on the in situ constrained diffusive equilibration in thin films (DET) technique, that allows the measurement of porewater alkalinity depth profiles at $2 \mathrm{~mm}$ resolution. ${ }^{15}$ This approach is an improvement on the coarse resolution offered by conventional coring techniques, but is highly labor-intensive and measures porewater alkalinity in one dimension only.

To understand alkalinity generating processes in the presence of the significant spatial heterogeneity that exists in sediments, new tools need to be developed that allow the representative measurement of key dissolved species at high-resolution and in two-dimensions. We have previously developed two-dimensional colorimetric diffusive equilibration in thin films (DET) techniques for iron(II) and dissolved reactive phosphorus, ${ }^{10,13,16}$ which meet these requirements, use inexpensive equipment and materials, and can be readily performed in the field. Here we describe, for the first time, a new high-resolution, two-dimensional DET method for measuring porewater distributions of total alkalinity in coastal sediments. The new method was used, in association with the existing iron(II) colorimetric DET technique, to measure porewater co-distributions in a coastal seagrass (Zostera capricorni) meadow in Queensland, Australia.

\section{Materials and Methods}

2.1. Reagents, materials and solutions. Ultra-pure deionized water $\left(>18 \mathrm{M} \Omega \mathrm{cm}^{-1}\right.$ Milli-Q Element, Millipore) was used to prepare all solutions. Bisacrylamide-cross linked polyacrylamide hydrogels, used for diffusive and reagent gel layers, were prepared as described previously ${ }^{13}$ with a minor modification: the total acrylamide/bisacrylamide monomer concentration was increased from $15 \%$ to $20 \%$ to increase the strength of the gels. Alkalinity standards were prepared from a commercially available certified sodium bicarbonate (Fluka, NIST Traceable) stock solution $(0.1$ mol L ${ }^{-1}$ ) diluted in $0.7 \mathrm{~mol} \mathrm{~L}^{-1}$ sodium chloride (Chem Supply, AR Grade). The DET colorimetric alkalinity reagent consisted of $200 \mathrm{mg} \mathrm{L}^{-1}$ bromophenol blue sodium salt (Sigma), $5 \times 10^{-3} \mathrm{~mol} \mathrm{~L}^{-1}$ formic acid (Fluka, AR Grade), and an ionic strength buffer at a concentration similar to the sample 
matrix ( $0.7 \mathrm{~mol} \mathrm{~L}^{-1}$ sodium chloride for coastal marine systems). This reagent was first described by Sarazin et al. ${ }^{17}$ for the spectrophotometric measurement of alkalinity in extracted porewater samples and was recently applied by Metzger et al. $^{15}$ to the constrained DET technique for measuring one dimensional porewater alkalinity profiles. The reagent for the measurement of iron(II) by colorimetric DET, $0.01 \mathrm{~mol} \mathrm{~L}^{-1}$ ferrozine (Sigma) in $0.1 \mathrm{~mol} \mathrm{~L}^{-1}$ acetate buffer, was prepared and used as previously described. ${ }^{16}$ The iron(II) colorimetric DET technique has been comprehensively evaluated in the literature - for more information on this technique refer to Bennett et al. ${ }^{16}$

The DET probe used in this study was custom-made from PVC and had exposure window dimensions of $150 \mathrm{~mm} \times 80 \mathrm{~mm}$. The probe components were washed in $10 \%(\mathrm{v} / \mathrm{v})$ nitric acid (Merck, AR Grade) for $24 \mathrm{~h}$ and thoroughly rinsed in deionized water prior to use. The probe was assembled as described previously ${ }^{13}$ and contained two layers of $0.8 \mathrm{~mm}$ thick polyacrylamide hydrogel (see Figure S1 in the supporting information). The two gel layers sample the sediment porewater at exactly the same location, allowing true co-distributions of alkalinity and iron(II) to be obtained. Prior to deployment, the assembled probe was deoxygenated for $12 \mathrm{~h}$ in $0.7 \mathrm{~mol} \mathrm{~L}^{-1} \mathrm{NaCl}$ (Chem Supply, AR Grade) sparged with high-purity nitrogen gas.

2.2. Calibration. Alkalinity standards were prepared at concentrations within the range $0-8$ meq $\mathrm{L}^{-}$ ${ }^{1}$ in $0.7 \mathrm{~mol} \mathrm{~L}^{-1}$ sodium chloride. Small gel sections used for calibration were equilibrated with standard solutions of known concentrations for $12 \mathrm{~h}$. Large gel sheets were also equilibrated for $12 \mathrm{~h}$ with the bromophenol blue/formic acid colorimetric reagent. Upon removal the reagent gels were held vertically to allow excess solution to drain away before being lain flat. A thin plastic strip was then wiped across the gel surface to remove any remaining reagent solution - this is important to ensure that the colorimetric reaction takes place within the gel. The calibration gels were placed onto a transparent polypropylene plastic sheet ( 170 $\mu \mathrm{m}$ thick) and immediately overlain with the reagent gel, followed by a second plastic sheet. After a reaction time of 10 minutes the gels were scanned directly into GIMP imaging software (Ver. 2.8, available for free from http://www.gimp.org) at 300 
dpi resolution using a commercially available flatbed scanner (Canon LiDE 210). These files were generated by the scanner in raw format (XCF format in GIMP, which preserves color channel information) and the RGB color space. A graphical summary of the calibration process is included in the Supporting Information (Figure S2).

It is important to note that the analytical performance characteristics of the colorimetric alkalinity reagent (bromophenol blue + formic acid) used by this DET method have been comprehensively evaluated by Sarazin et al. ${ }^{17}$ They found that this reagent, when calibrated spectrophotometrically with bicarbonate standard solutions, accurately responded to multiple alkalinity-contributing species such as phosphate, ammonia and sulfide. Comparison with potentiometric titration showed agreement, typically within $1 \%$, between the two methods. Our colorimetric DET method utilizes the same chemical principles as described by Sarazin et al., ${ }^{17}$ but uses computer imaging densitometry, rather than spectrophotometry, as the detection method.

2.3. Computer imaging densitometry. To maximize the sensitivity of the technique, a color channel filter was used for grayscale conversion. The primary color of the unreacted colorimetric reagent is green, which changes color to blue when exposed to alkalinity generating species. In order to decrease the optical density of the background signal and increase that of the analytical signal, the green channel was increased to $150 \%$ and the blue channel decreased to $-50 \%$ during the conversion to grayscale. This combination resulted in maximum sensitivity without any decrease in measurement range. The processed and converted files were rescaled so that 1 pixel equaled $1 \mathrm{~mm}^{2}$ and saved in TIFF format. Image files were then opened with Image $\mathrm{J}$ (available for free from http://rsbweb.nih.gov/ij/), which was used to measure the pixel grayscale intensities. For calibration, the average grayscale intensity of 100 pixels $\left(100 \mathrm{~mm}^{2}\right)$ was measured for each standard concentration and plotted using Microsoft Excel 2010. For deployed DET probes, the grayscale intensity for each pixel of the entire image was measured ('Save As' > 'Text Image') and results were plotted as high-resolution, two-dimensional filled contour plots using Matlab (Version 
R2012a), after using the calibration curve to convert grayscale intensities into alkalinity concentrations. One-dimensional profiles can be generated from the two-dimensional data by laterally averaging the results at each depth and plotting the mean and standard deviation. It should be noted that although lateral diffusion of solutes within the gel should be limited to a distance equal to the gel thickness $(0.8 \mathrm{~mm}),{ }^{18}$ diffusional relaxation during the colorimetric reaction and scanning steps will reduce the attainable resolution to between 1 and $2 \mathrm{~mm}^{2} .^{13}$ Detailed instructions for scanning gels, processing image files and graphing two-dimensional data are included in the Supporting Information (Section S1).

2.4. Performance characteristics. The detection limits of the method (MDL) were calculated as three times the standard deviation of the grayscale intensity of the 0.5 meq $\mathrm{L}^{-1}$ alkalinity standard plus the grayscale intensity of the blank, analysed at a resolution of $1 \mathrm{~mm}^{2}=1$ pixel ( $\mathrm{n}=100$ pixels). The accuracy and reproducibility of the method was evaluated by analyzing a certified sodium bicarbonate solution (NIST Traceable $0.1 \mathrm{~mol} \mathrm{~L}^{-1}$, Fluka), independent of the calibration standards, prepared at 3 meq $\mathrm{L}^{-1}$. Sections of gel were equilibrated with this solution and analyzed as described previously. The method was also directly compared to potentiometric titration, to further assess the accuracy of this approach in the context of real samples. Two samples were collected locally from the Gold Coast Broadwater, Queensland, Australia: a surface coastal seawater sample and a composite sediment porewater sample, and analysed by both methods. Details of the potentiometric titration procedure and the comparison with the colorimetric DET technique are given in the Supporting Information (Section S2).

2.5. Field deployment. The method was applied in the Gold Coast Broadwater, Queensland, Australia; a semi-enclosed lagoon receiving freshwater inputs from four rivers. A DET probe, containing two $0.8 \mathrm{~mm}$ thick gel layers, one on top of the other, was deployed in sediment occupied by the seagrass Z . capricorni. This probe configuration exposes both gel layers to exactly the same sediment section allowing true co-distributions of porewater alkalinity and iron(II) to be obtained. 
The probe was retrieved after $\sim 24 \mathrm{~h}$ and the gels immediately cut out using a scalpel. Gels were then placed onto reagent gels equilibrated with the colorimetric alkalinity and iron(II) reagents, respectively. The gels were then overlain by a second transparent plastic sheet and allowed to react for 10 minutes, after which time they were scanned. Scanned images were processed using the computer imaging densitometry procedure described earlier for alkalinity measurements and that of Bennett et al., ${ }^{16}$ for iron(II) measurements. Raw color and processed grayscale images for alkalinity are shown in the Supporting Information (Figure S3).

Minimization of the delay between removal of the probe from the sediment and the staining step is important to limit diffusional relaxation of solute distributions in the gels and to avoid potential interferences associated with exposure to the atmosphere, such as oxidation of iron(II) . The sample processing and reaction step could be performed in a field-based anoxic glove bag to minimize interference due to atmospheric exposure, although the benefit of this is likely to be minor under most circumstances. ${ }^{13}$

\section{Results and Discussion}

3.1. Calibration. Upon exposure of the sample gel to the reagent gel, alkalinity-generating species neutralize the formic acid $\left(\mathrm{pK}_{\mathrm{a}}=3.43\right)$, increasing the $\mathrm{pH}$ of the colorimetric reagent. As the $\mathrm{pH}$ approaches the $p K_{\mathrm{a}}$ of bromophenol blue (3.86), it dissociates into its conjugate base and an intense blue color is generated. ${ }^{17}$ The formic acid concentration used in this study $\left(5 \times 10^{-3} \mathrm{~mol} \mathrm{~L}^{-1}\right)$ allows the measurement of up to 8 meq $\mathrm{L}^{-1}$ alkalinity (Figure 1) and ensures that a range of color intensities are observed with varying alkalinity. The upper measurement limit of this technique can be extended by increasing the formic acid concentration in the colorimetric reagent so that a higher concentration of alkalinity generating species is required to cause the same degree of bromophenol blue dissociation. ${ }^{17}$ This would require a recalibration of the method with the modified reagent and an appropriate set of standards. 


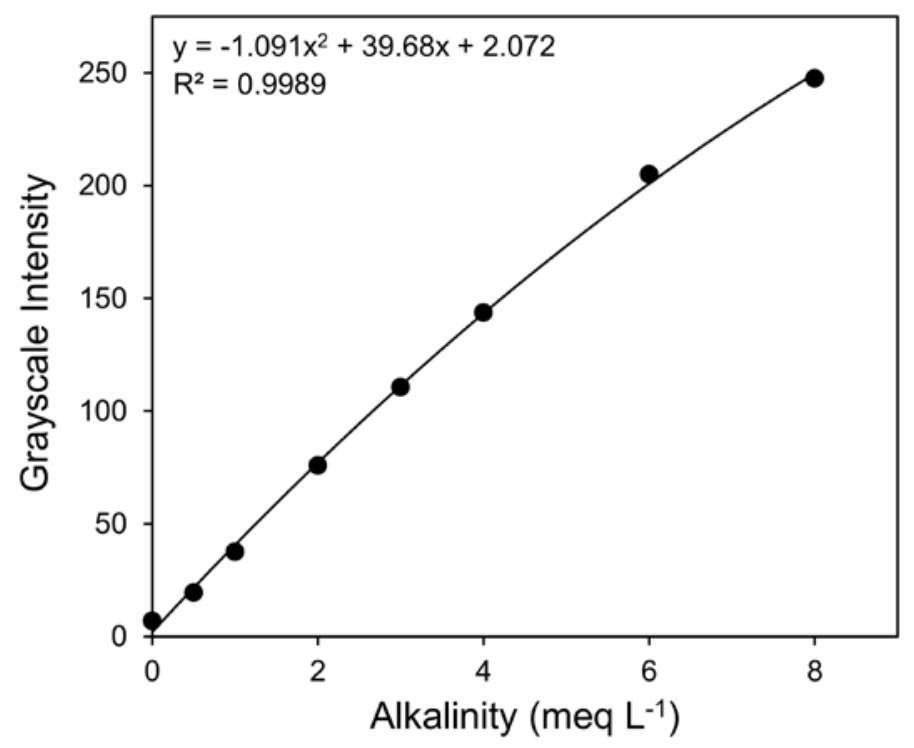

Figure 1. Calibration curve for alkalinity DET with a colorimetric reagent consisting of $200 \mathrm{mg} \mathrm{L}^{-1}$ bromophenol blue, $5 \times 10^{-3} \mathrm{~mol} \mathrm{~L}^{-1}$ formic acid and $0.7 \mathrm{~mol} \mathrm{~L}^{-1}$ sodium chloride. Each point represents the mean grayscale intensity of 100 replicate pixels of a scanned standard gel. Error bars showing \pm 1 standard deviation of the mean are present but not visible.

The calibration data was well fitted by a second order polynomial function $\left(\mathrm{R}^{2}=0.9989\right)$. A third order polynomial fitted the data slightly better $\left(\mathrm{R}^{2}=0.9997\right)$, but due to the difficulty in using this function as a calibration curve for large datasets, the second order polynomial was preferred. The colorimetric method on which this technique is based was also calibrated with a second order polynomial function. ${ }^{17}$ Equation 1, which is derived from the second order polynomial function and the quadratic equation, was used to calculate alkalinity $(x)$ from the measured grayscale intensities (y) of deployed and analysed gels:

$$
x=\frac{-39.68+\sqrt{39.68^{2}-(4 \times-1.091 \times(2.072-y))}}{2 \times-1.091}
$$

3.2. Performance characteristics. The method detection limit of this technique is 0.2 meq $\mathrm{L}^{-1}$, which is sufficiently low for the measurement of alkalinity in coastal sediments where concentrations are typically above 2 meq $\mathrm{L}^{-1}$.2, 17 The measured recovery of the quality control standard prepared at 3 meq $\mathrm{L}^{-1}$ from a certified sodium bicarbonate stock solution was $103 \pm 0.6 \%$ $(n=100)$. 
The colorimetric DET method compared well with potentiometric titration for natural surface seawater and coastal sediment porewater samples (Table 1), with differences between the two methods less than 5\%. Although this degree of accuracy is lower than reported by Sarazin et al. ${ }^{17}$ for their spectrophotometric bromophenol blue method, who reported agreement with potentiometric titrations to $1 \%$, it is sufficient considering the rapidity, ease of use, high-resolution and twodimensional capabilities of the colorimetric DET method.

Table 1. Total alkalinity concentrations (meq $\left.\mathrm{L}^{-1}\right)$ measured by colorimetric DET $\left(\mathrm{C}_{\mathrm{DET}}\right)$ and potentiometric titration $\left(\mathrm{C}_{\text {TITRATION }}\right)$ for surface seawater and coastal sediment porewater samples.

\begin{tabular}{lccc}
\hline Sample Type & $\boldsymbol{C}_{\boldsymbol{D E T}}^{\boldsymbol{a}}\left(\boldsymbol{m e q ~ L}^{-\mathbf{1}}\right)$ & $\boldsymbol{C}_{\text {TITRATION }}^{\boldsymbol{b}}\left(\mathbf{m e q ~ L}^{-1}\right)$ & $\boldsymbol{\Delta}\left(\boldsymbol{C}_{\text {DET }}-\boldsymbol{C}_{\text {TITRATION }}, \boldsymbol{\%}\right)^{\boldsymbol{c}}$ \\
\hline Surface Seawater & 2.405 & 2.297 & $+4.7 \%$ \\
Sediment Porewater & 4.069 & 3.901 & $+4.3 \%$
\end{tabular}

${ }^{a}$ Average of duplicate DET measurements. Duplicates agreed to within $1.6 \%$ for both surface seawater and sediment porewater.

${ }^{\mathrm{b}}$ Average of duplicate titration measurements. Duplicates agreed to within $0.3 \%$ for surface seawater and $1.2 \%$ for sediment porewater.

${ }^{c}$ The \% difference between $\mathrm{C}_{\mathrm{DET}}$ compared to $\mathrm{C}_{\text {TITRATION }}$.

The DET technique effectively samples only microliters of porewater, compared to the milliliters of porewater required for titration analysis. ${ }^{18,19}$ This extremely high volumetric resolution, in addition to the in situ nature of the sampling, minimizes potential artifacts that arise from the mixing of porewater solutes during analysis that were originally spatially separated in situ. While the colorimetric DET technique may not be as 'accurate' as a potentiometric titration, we propose it provides a much more representative measurement of porewater alkalinity, as it avoids the spatial averaging of values that occurs due to the large volume of porewater required for potentiometric analysis and potential artifacts that can occur through chemical reaction during porewater mixing during extraction. This is particularly important when investigating fine-scale biogeochemical processes in heterogeneous coastal sediments, where porewater solute concentrations show large small scale variations and zones of high concentration of mutually reactive species may occur within one to a few millimeters of each other. ${ }^{9,11,13}$ In these systems, the capacity to measure representative small-scale variations in porewater alkalinity and its relationship to other porewater solutes and 
sediment features is of greater importance than the accuracy of the absolute concentration value per se.

Finally, it is important to note that this method is not capable of the same measurement resolution as potentiometric titration methods due to the effective resolution for a given measurement range being limited by the number of possible grayscale intervals (256). Therefore, the maximum attainable resolution when using a colorimetric reagent with $5 \times 10^{-3} \mathrm{~mol} \mathrm{~L}^{-1}$ formic acid (as shown in Figure 1) is 0.035 meq $L^{-1}$. To improve the resolution of the measurement, the formic acid concentration could be lowered, resulting in the same grayscale increase over a smaller concentration range.

3.3. Field Deployment. The deployment of this new method in the sediment of a seagrass meadow revealed, for the first time, the heterogeneity of alkalinity distributions in the seagrass rhizosphere (Figure 2). In addition, this approach allowed co-distributions of iron(II) to be measured at the same sediment location, allowing direct comparison of these analytes. In addition, we have recently published preliminary results from this method where it was used to characterize biogeochemical processes in modern stromatolites, revealing highly heterogeneous porewater alkalinity distributions. $^{20}$ 

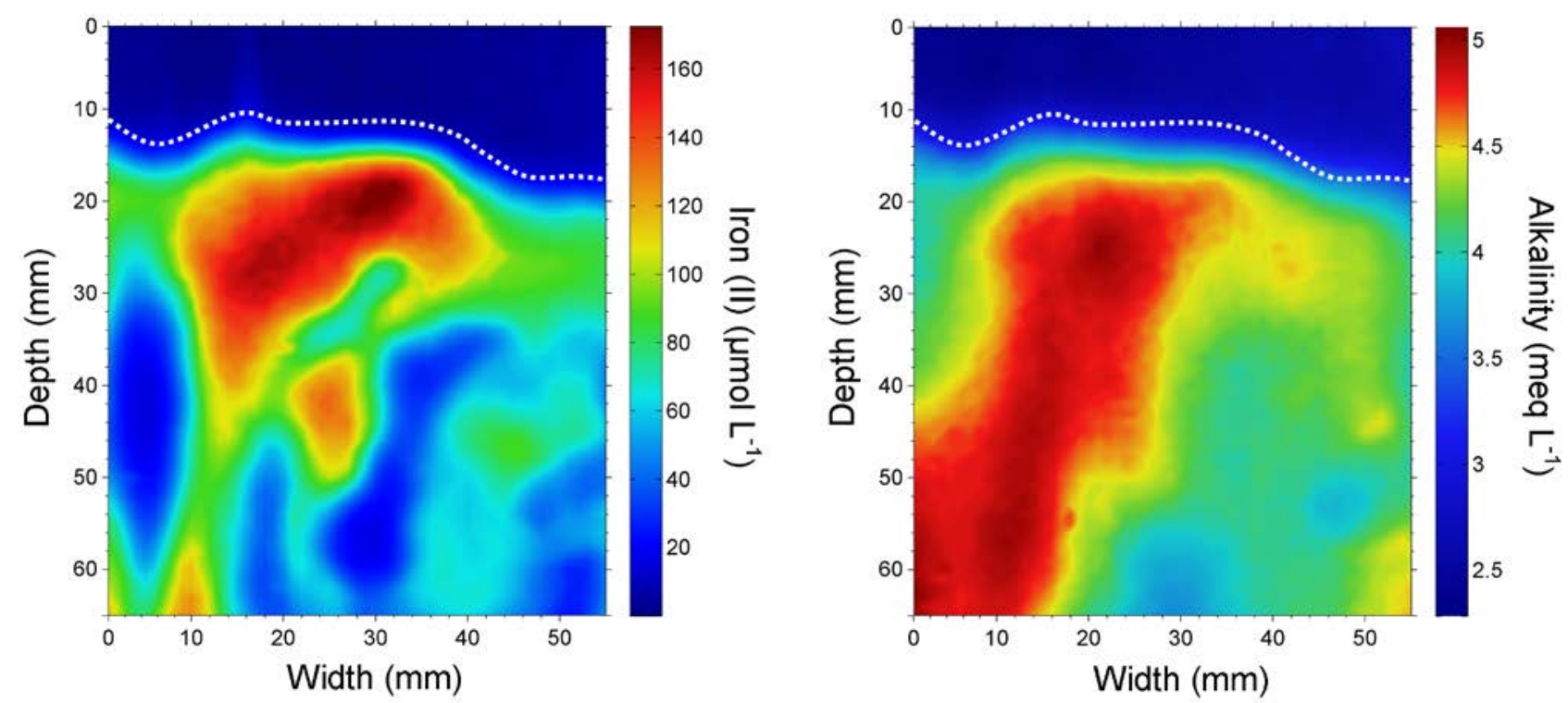

Figure 2. Two-dimensional distributions $(6.5 \mathrm{~cm}$ by $5.5 \mathrm{~cm})$ of iron(II) and alkalinity in the porewater of a coastal marine sediment colonized by the seagrass $Z$. capricorni. False color images were generated as filled contour plots in Matlab (R2012a) and the scales adjusted to highlight relevant features for comparison between the two distributions. The approximate sediment water interface (shown as the dotted white line) was determined based on the iron (II) distribution, and superimposed onto the alkalinity distribution. Due to the uneven SWI, the depth scale indicates distance from the top of the sampler.

Alkalinity exhibited a highly heterogeneous distribution in the sediment porewater over fine spatial scales (mm). Concentrations increase from $2.5-3$ meq $\mathrm{L}^{-1}$ in the water column to over 5 meq $\mathrm{L}^{-1}$ in some areas of the sediment porewater. Some of this increase is clearly associated with organic matter remineralization, as demonstrated by the co-location of elevated alkalinity with iron(II) hotspots. Microbial dissimilatory iron reduction is one pathway of organic matter remineralization in coastal sediments that contributes to alkalinity generation. ${ }^{3}$

A high degree of heterogeneity on small spatial scales is more apparent in the iron(II) distribution, likely due to the presence of seagrass roots and burrowing infauna, ${ }^{11,14}$ as iron(II) responds to redox changes. Seagrass tissues contain a system of lacunae that facilitate oxygen transport to roots, part of which is lost by diffusion to the sediment where it creates oxic niches within the otherwise anoxic sediment. $^{21,22}$ This allows seagrasses to survive in sediments that contain reduced chemical species 
that can negatively impact their growth and survival, such as sulfide. ${ }^{23}$ Additionally, seagrass roots also excrete labile photosynthates to the surrounding sediments stimulating both aerobic and anaerobic respirations. ${ }^{24}$ Thus, it would be expected that the presence of roots would result in heterogeneous distributions of both alkalinity and iron(II) due to small scale variations in overall respiration rates, rapid oxidation and precipitation of iron(II) as iron (III) oxyhydroxides in oxic microzones, which decreases alkalinity, or precipitation of iron(II) as FeS by sulfide, which itself contributes to alkalinity, in anoxic zones. ${ }^{3}$

Dissolved iron(II) was generally absent in the water column, as expected due to oxic conditons, but was present at over $160 \mu \mathrm{mol} \mathrm{L}-1$ in the large hotspot in the top $25 \mathrm{~mm}$ of the sediment. While there is a clear correlation between porewater alkalinity and iron(II) distributions, the alkalinity distribution is visibly more diffuse and less well defined compared to that of iron(II). This is partly because of the relatively high background concentration of alkalinity due to the concentration of bicarbonate in seawater. In addition, the primary species that contribute to total alkalinity, such as carbonate and bicarbonate, are much less redox-active compared with iron(II), so the observed distribution represents the production, consumption and diffusion of alkalinity, in contrast to iron(II) where oxidation and precipitation also play a large role in determining the spatial distribution, as discussed above. Additionally, other products of microbial organic matter turnover such as sulfide and ammonia, whose distributions are also known to exhibit large spatial and temporal variability in the seagrass rhizosphere, also contribute to alkalinity. ${ }^{14}$

These two-dimensional distributions of porewater iron(II) and alkalinity can also be represented as one-dimensional concentration profiles through lateral averaging of the data (Figure 3). These plots display the average horizontal concentration and standard deviation, providing a simpler representation of the variation in porewater solute concentration over small spatial scales. This data is similar to that obtained using conventional sediment porewater analysis techniques, although because the average is determined from two-dimensional distributions, the data is not confounded by 
the artifacts associated with the bulk mixing of porewater and sediment (and the unavoidable chemical reactions) that occurs during most porewater extraction processes. It is clear, however, that this method of data representation fails to clearly show the significant spatial variability displayed in the two-dimensional distributions (Figure 2).
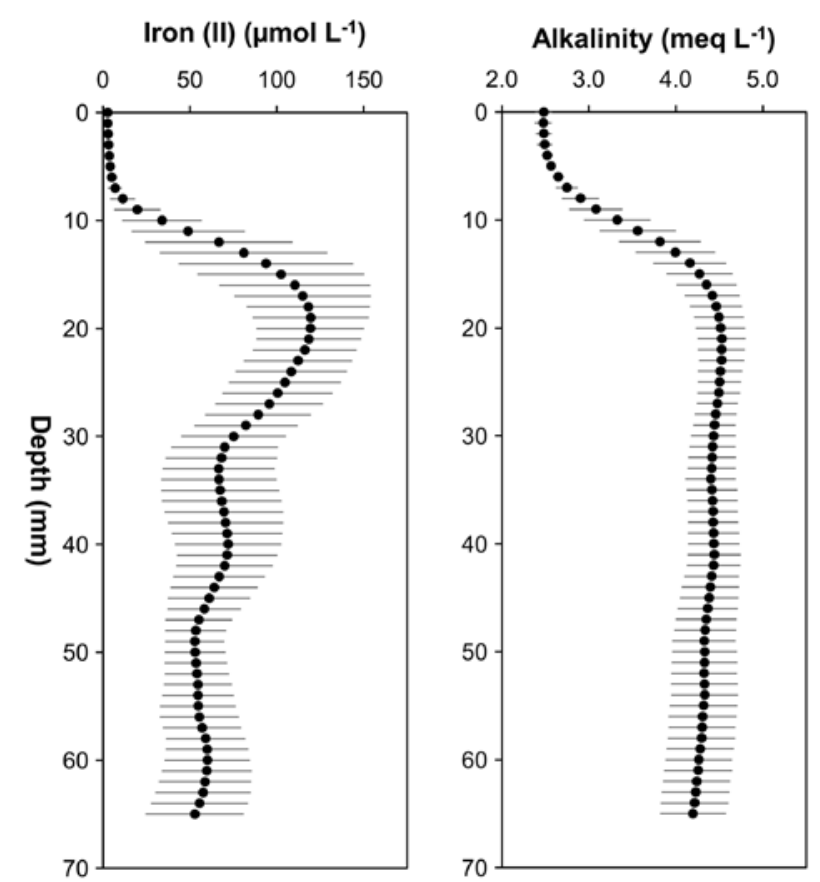

Figure 3. One-dimensional profiles of the laterally averaged, two-dimensional iron(II) and alkalinity data presented in Figure 2. Error bars represent \pm standard deviation of the mean. Due to the uneven SWI, the depth scale indicates distance from the top of the sampler. The SWI is located at approximately 10-15 mm depth (as shown in Figure 2).

The described method for measuring high resolution, two-dimensional distributions of porewater alkalinity has, for the first time, revealed the complexity that occurs at small spatial scales in coastal marine sediments. Attempting to characterize alkalinity in this sediment using conventional coring and porewater analysis techniques would result in highly unrepresentative data. ${ }^{9}$ The method we have described here, although not as precise as a potentiometric titration, will yield more useful data as a result of the high degree of representativeness that this two-dimensional sampling and analysis method provides. Further, this method can be combined with ease with existing gel-based techniques for measuring iron(II), sulfide ${ }^{25}$ and phosphate ${ }^{10}$ to determine co-distributions, as shown for iron(II) and alkalinity in this study. Combination of the alkalinity DET method with planar optode or 
microelectrode measurements of $\mathrm{pH}$ at high-resolution and in two dimensions would allow investigation of the carbon cycle in marine sediments at unprecedented detail. Deployment of this technique would also be possible in cores collected from shelf and open ocean sediments, which would provide new insight into key biogeochemical pathways of organic matter remineralization in those systems. Future studies will focus on using this new method for investigating high-resolution, two-dimensional alkalinity distributions within coastal, shelf and open ocean marine sediments to further characterize the biogeochemical processes of alkalinity generation.

\section{References}

1. Heinze, C.; Maier-Reimer, E.; Winguth, A. M.; Archer, D., A global oceanic sediment model for long-term climate studies. Glob. Biogeochem. Cycles 1999, 13, (1), 221-250.

2. Haraldsson, C.; Anderson, L. G.; Hassellöv, M.; Hulth, S.; Olsson, K., Rapid, high-precision potentiometric titration of alkalinity in ocean and sediment pore waters. Deep Sea Research Part I: Oceanographic Research Papers 1997, 44, (12), 2031-2044.

3. Krumins, V.; Gehlen, M.; Arndt, S.; Van Cappellen, P.; Regnier, P., Dissolved inorganic carbon and alkalinity fluxes from coastal marine sediments: model estimates for different shelf environments and sensitivity to global change. Biogeosciences 2013, 10, 371-398.

4. Schiff, S.; Anderson, R., Alkalinity production in epilimnetic sediments: Acidic and nonacidic lakes. Water, Air, Soil Pollut. 1986, 31, (3), 941-948.

5. Henriksen, A., A simple approach for identifying and measuring acidification of freshwater. Nature 1979, 278, 542-545.

6. Berner, R.; Scott, M.; Thomlinson, C., Carbonate alkalinity in the pore waters of anoxic marine sediments. Limnol. Oceanogr. 1970, 15, 544-549.

7. Thomas, H.; Schiettecatte, L.-S.; Suykens, K.; Koné, Y.; Shadwick, E.; Prowe, F.; Bozec, Y.; de Baar, H. J.; Borges, A., Enhanced ocean carbon storage from anaerobic alkalinity generation in coastal sediments. Biogeosciences (BG) 2009, 6, (2), 267-274.

8. $\quad$ Faber, P.; Kessler, A.; Bull, J.; McKelvie, I.; Meysman, F.; Cook, P., The role of alkalinity generation in controlling the fluxes of $\mathrm{CO}_{2}$ during exposure and inundation on tidal flats. Biogeosciences Discuss. 2012, 9, (5), 5445-5469.

9. Stockdale, A.; Davison, W.; Zhang, H., Micro-scale biogeochemical heterogeneity in sediments: A review of available technology and observed evidence. Earth-Sci. Rev. 2009, 92, (1-2), 81-97.

10. Pages, A.; Teasdale, P. R.; Robertson, D.; Bennett, W. W.; Schäfer, J.; Welsh, D. T., Representative measurement of two-dimensional reactive phosphate distributions and co-distributed iron (II) and sulfide in seagrass sediment porewaters. Chemosphere 2011, 85, (8), 1256-1261. 
11. Robertson, D.; Welsh, D. T.; Teasdale, P. R., Investigating biogenic heterogeneity in coastal sediments with two-dimensional measurements of iron (II) and sulfide. Environ. Chem. 2009, 6, (1), 60-69.

12. Neal, C., Alkalinity measurements within natural waters: towards a standardised approach. Sci. Total Environ. 2001, 265, (1-3), 99-113.

13. Robertson, D.; Teasdale, P. R.; Welsh, D. T., A novel gel-based technique for the high resolution, two-dimensional determination of iron (II) and sulfide in sediment. Limnol. Oceanogr. Meth. 2008, 6, 502-512.

14. Pagès, A.; Welsh, D. T.; Robertson, D.; Panther, J. G.; Schäfer, J.; Tomlinson, R. B.; Teasdale, P. R., Diurnal shifts in co-distributions of sulfide and iron (II) and profiles of phosphate and ammonium in the rhizosphere of Zostera capricorni. Estuar. Coast. Shelf. Sci. 2012, 115, 282290.

15. Metzger, E.; Viollier, E.; Simonucci, C.; Prévot, F.; Langlet, D.; Jézéquel, D., Millimeterscale alkalinity measurement in marine sediment using DET probes and colorimetric determination. Water Res. 2013, (In Press - Accepted Manuscript), DOI: 10.1016/j.watres.2013.06.038.

16. Bennett, W. W.; Teasdale, P. R.; Welsh, D. T.; Panther, J. G.; Jolley, D. F., Optimization of colorimetric DET technique for the in situ, two-dimensional measurement of iron(II) distributions in sediment porewaters. Talanta 2012, 88, 490-495.

17. Sarazin, G.; Michard, G.; Prevot, F., A rapid and accurate spectroscopic method for alkalinity measurements in sea water samples. Water Res. 1999, 33, (1), 290-294.

18. Harper, M. P.; Davison, W.; Tych, W., Temporal, spatial, and resolution constraints for in situ sampling devices using diffusional equilibration: Dialysis and DET. Environ. Sci. Technol. 1997, 31, (11), 3110-3119.

19. Zhang, H.; Davison, W.; Mortimer, R. J. G.; Krom, M. D.; Hayes, P. J.; Davies, I. M., Localised remobilization of metals in a marine sediment. Sci. Total Environ. 2002, 296, (1-3), 175187.

20. Pagès, A.; Grice, K.; Vacher, M.; Welsh, D. T.; Teasdale, P. R.; Bennett, W. W.; Greenwood, P., Characterising microbial communities and processes in a modern stromatolite (Shark Bay) using lipid biomarkers and two-dimensional distributions of porewater solutes. Environmental Microbiology 2014, DOI: 10.1111/1462-2920.12378.

21. Borum, J.; Sand-Jensen, K.; Binzer, T.; Pedersen, O.; Greve, T., Oxygen Movement in Seagrasses. In Seagrasses: Biology, Ecology and Conservation, Springer Netherlands: 2006; pp 255270.

22. Frederiksen, M. S.; Glud, R. N., Oxygen dynamics in the rhizosphere of Zostera marina: A two-dimensional planar optode study. Limnol. Oceanogr 2006, 51, (2), 1072-1083.

23. Terrados, J.; Duarte, C. M.; Kamp-Nielsen, L.; Agawin, N. S. R.; Gacia, E.; Lacap, D.; Fortes, M. D.; Borum, J.; Lubanski, M.; Greve, T., Are seagrass growth and survival constrained by the reducing conditions of the sediment? Aquat. Bot. 1999, 65, (1-4), 175-197.

24. Welsh, D.; Wellsbury, P.; Bourguès, S.; Wit, R.; Herbert, R., Relationship between porewater organic carbon content, sulphate reduction and nitrogen fixation (acetylene reduction) in the rhizosphere of Zostera noltii. In Coastal Lagoon Eutrophication and ANaerobic Processes (C.L.E.AN.), Caumette, P.; Castel, J.; Herbert, R., Eds. Springer Netherlands: 1996; Vol. 117, pp 175-183. 
25. Teasdale, P.; Hayward, S.; Davison, W., In situ, high-resolution measurement of dissolved sulfide using diffusive gradients in thin films with computer-imaging densitometry. Anal. Chem. 1999, 71, (11), 2186-2191. 